\title{
Parental spanking and subsequent risk for child aggression in father-involved families of young children ${ }^{2 / 2}$
}

\author{
Shawna J. Lee ${ }^{\mathrm{a}, *}$, Catherine A. Taylor ${ }^{\mathrm{b}, 1}$, Inna Altschul ${ }^{\mathrm{c}, 2}$, Janet C. Rice ${ }^{\mathrm{d}}$ \\ ${ }^{a}$ University of Michigan, School of Social Work E Institute for Social Research, 1080 South University Avenue, Ann Arbor, MI 48109-1106, United States \\ b Tulane University, School of Public Health and Tropical Medicine, United States \\ c University of Denver, Graduate School of Social Work, United States \\ d Tulane University, School of Public Health and Tropical Medicine, Department of Biostatistics, United States
}

\section{A R T I C L E I N F O}

\section{Article history:}

Received 19 October 2012

Received in revised form 27 May 2013

Accepted 28 May 2013

Available online 7 June 2013

\section{Keywords:}

Corporal punishment

Physical aggression

Physical discipline

Fragile families

Child Behavior Checklist

Child maltreatment

\begin{abstract}
A B S T R A C T
This study examined separate and combined maternal and paternal use of spanking with children at age 3 and children's subsequent aggressive behavior at age 5 . The sample was derived from a birth cohort study and included families $(n=923)$ in which both parents lived with the child at age 3 . In this sample, $44 \%$ of 3 -year-olds were spanked 2 times or more in the past month by either parent or both parents. In separate analyses, being spanked more than twice in the prior month at age 3 , by either mother or father, was associated with increased child aggression at 5 years. In combined analyses, there was a dose-response association; the greatest risk for child aggression was reported when both parents spanked more than twice in the prior month (adjusted odds ratio: 2.01; [confidence interval: 1.03-3.94]). Violence prevention initiatives should target and engage mothers and fathers in anticipatory guidance efforts aimed at increasing the use of effective and non-aggressive child discipline techniques and reducing the use of spanking.
\end{abstract}

(c) 2013 Elsevier Ltd. All rights reserved.

\section{Introduction}

Numerous studies have linked spanking to increased child aggression, antisocial behavior, and mental health problems (e.g., Berlin, Ispa, Fine, et al., 2009; Gershoff, 2002; Grogan-Kaylor, 2005; MaguireJack, Gromoske, \& Berger, 2012; Taylor, Manganello, Lee, \& Rice, 2010). Other studies, however, have raised questions about the magnitude of spanking's impact on children (e.g., Ferguson, 2012; Larzelere \& Kuhn, 2005; Morris \& Gibson, 2011). Spanking remains among parents' most common disciplinary practices. Earlier studies suggested that about $94 \%$ of parents had used some form of spanking to discipline their 4 year old children, and approximately one-third have spanked their infants (Straus \& Stewart, 1999). More recently, in a large, urban, population-based study, two-thirds of 3-year-old children had been

Abbreviations: FFCWS, Fragile Families and Child Wellbeing Study; CTSPC, ParentChild Conflict Tactics Scale; CIDI-SF, Composite International Diagnostic Interview Short Form; US, United States; AOR, adjusted odds ratios; CI, 95\% confidence interval. is Funding: The Fragile Families and Child Wellbeing Study is funded by NICHD grant numbers R01HD36916, R01HD39135, and R01HD40421, as well as a consortium of private foundations and other government agencies. The research reported in this study was also partially supported by the National Institute of Child Health and Human Development (5K01HD058733) to Taylor.

* Corresponding author. Tel.: +1 7347636565 (office); fax: +1 7347633372 .

E-mail addresses: shawnal@umich.edu (S.J. Lee), ctaylor5@tulane.edu (C.A. Taylor), inna@du.edu (I. Altschul), jrice@tulane.edu (J.C. Rice).

${ }^{1}$ Tel.: + 15049880292 (office); fax: + 15049883540

${ }^{2}$ Tel.: +1 3038714243 (office); fax: +13038712845. spanked by one or both parents in the past month (Taylor, Lee, Guterman, \& Rice, 2010). Reports from both mothers and children indicate that over $80 \%$ of children have been spanked by the time they reach 9 or 10 years of age (Vittrup \& Holden, 2010).

A notable gap in understanding parental use of spanking and, by extension, changing it, exists because the majority of research has focused only on mothers' use of spanking (e.g., Berlin et al., 2009; Campbell, Pierce, Moore, Marakovitz, \& Newby, 1996; Grogan-Kaylor, 2004, 2005; Kandel \& Wu, 1995; Lansford et al., 2009; Scholer, Walkowski, \& Bickman, 2008; Singer, Singer, \& Rapaczynski, 1984; Taylor, Manganello, et al., 2010). Parenting education and intervention efforts in social work and primary care settings also tend to recruit mothers (Kaminski, Valle, Filene, \& Boyle, 2008; Scholer, Hudnut-Beumler, \& Dietrich, 2010). The influence that fathers' use of spanking has on child outcomes is not clear. The information gap regarding fathers' use of spanking is problematic, since children in two-parent households receive discipline from, and thus are influenced by, mothers and fathers. For example, in the previously cited study, $65 \%$ of 3-year-old children had been spanked by one or both parents in the previous month: $12.7 \%$ by fathers only, $23.5 \%$ by mothers only, and $29.1 \%$ by both parents (Taylor, Lee, et al., 2010).

Even though in two-parent households mothers assume most of the responsibility for day-to-day care for young children, evidence indicates that fathers may engage in relatively more punishment and harsh discipline of children (Straus \& Stewart, 1999). The limited evidence that does exist suggests that paternal spanking outcomes may 
be similar to maternal spanking effects. For example, similar to research among mothers who spank (Maguire-Jack et al., 2012) paternal spanking was associated with increased child aggression in adolescence (Prinzie, Onghena, \& Hellinckx, 2006). However, this study did not examine paternal spanking in early childhood (Prinzie et al., 2006). A more thorough examination and clearer understanding of the influence of fathers is important, especially in early childhood, since both spanking and levels of child aggression peak during these years (Straus \& Stewart, 1999) and consistent reliance on spanking that begins at very early ages may contribute to less optimal outcomes for children (Lansford, Criss, Dodge, Shaw, Pettit \& Bates, 2009).

Furthermore, it is important to assess mothers' and fathers' influences independently and conjointly because, although mothers and fathers use positive and negative parenting behaviors with similar frequencies (Cabrera, Shannon, \& Tamis-LeMonda, 2007; TamisLeMonda, Shannon, Cabera, \& Lamb, 2004), parenting styles do not necessarily overlap within couples (Martin, Ryan, \& Brooks-Gunn, 2007; Ryan, Martin, \& Brooks-Gunn, 2006; Winsler, Madigan, \& Aquilino, 2005). For example, one parent may discipline the child more frequently because the other parent does not. Alternatively, mothers' and fathers' behaviors may reinforce each other, a pattern which compounds the positive or negative effects on children when the influence of mothers' and fathers' behaviors are considered simultaneously (Ryan et al., 2006). Therefore, analyses that rely solely on reports of maternal spanking may underestimate the child's exposure to discipline. This study, which seeks to extend knowledge on how fathers' parenting behaviors influence the development of their young children, will provide information on how to better design intervention and education programs that reach fathers.

\subsection{The current study}

This study examines the separate and combined influence of maternal and paternal spanking on the children's subsequent aggressive behavior at age 5 , using data from families where both parents resided in the home when their child was 3 years old. The study families were defined as father-involved, because all fathers were living in the household at the time of the assessment of spanking. Further, all fathers self-identified as the biological parent of the study target child at the child's birth. Our first research goal examined whether fathers' spanking influences the development of child aggressive behavior, while controlling for such important confounds as child's exposure to more serious forms of maltreatment. Our second research goal examined the additive effect of both maternal and paternal spanking and considered whether combined parental spanking influences child aggression in a manner resembling patterns observed when each parent is examined separately.

This study addressed important methodological limitations inherent in prior studies that have examined the influence of maternal spanking on children, as reviewed elsewhere (Taylor, Manganello, et al., 2010). First, many prior studies examining the influence of spanking on child wellbeing relied on clinical or child protective services (CPS) samples, which may introduce selection bias when interpreting study results. We conducted prospective analysis of a community-based sample of diverse urban families. Second, children who are more difficult to parent may elicit harsher parental discipline (Beauchaine, Webster Stratton, \& Reid, 2005; Belsky, 1984; Day, Peterson, \& McCracken, 1998); therefore, it is important to control for the child's level of aggressive behavior (Maguire-Jack et al., 2012). In this study, we controlled for the child's baseline level of aggression at age 3 and examined whether parental spanking was associated with a subsequent increase in child aggression measured at age 5 . We also used longitudinal data to account for the sequencing of the association between spanking, measured at age 3 , and children's outcomes, measured at age 5 . Fourth, factors such as physical and psychological maltreatment of the child (Smith, 2012); intimate partner aggression and violence; parental stress; and alcohol use have been linked to spanking (Black, Heyman, \& Smith, 2001; Lee, Perron, Taylor, \& Guterman, 2011; Slep \& O'Leary, 2005; Taylor, Lee, et al., 2010; Taylor, Manganello, et al., 2010; Zolotor, Theodore, Chang, Berkoff, \& Runyan, 2008) and to childhood aggression. The presence of these factors may confound the association between spanking and aggressive behavior (Brennan, Hall, Bor, Najman, \& Williams, 2003; Koblinsky, Kuvalanka, \& Randolph, 2006; McFarlane, Groff, O'Brien, \& Watson, 2003; Meadows, McLanahan, \& Brooks-Gunn, 2007; Owens \& Shaw, 2003). In this study, we controlled for both such factors in our final models and for the child's daily television viewing, given that exposure to media is also associated with increased risk of child aggression (Manganello \& Taylor, 2009). Finally, we controlled for each father's self-report of involvement in daily care of the child, because fathers' levels of involvement vary considerably, even among in-residence, biological fathers.

\section{Method}

\subsection{Participants}

This sample was obtained from the Fragile Families and Child Wellbeing Study (FFCWS), a longitudinal cohort study of families. The original cohort $(\mathrm{N}=4898$ ) was obtained between 1998 and 2000 by sampling new births within hospitals from cities with populations over 200,000. Non-marital births were oversampled relative to marital births, because parents in non-marital unions are at greater risk for poverty and relationship instability (participants whose relationships are characterized by these dynamics are termed fragile families). The institutional review boards at Columbia University and Princeton University approved participant recruitment procedures (Reichman, Teitler, Garfinkel, \& McLanahan, 2001). Responding fathers were recruited at hospitals and by telephone. Fathers were identified as the biological father of the target child. Verbal and written informed consent was obtained from participants at each interview, and participants were compensated for their involvement in the study. Detailed description of the study design was published previously (Reichman et al., 2001).

Core interviews with mothers and fathers were conducted across multiple waves: baseline (at index children's birth) and when children were 1, 3, and 5 years of age. The add-on In-Home Longitudinal Study of Pre-School Aged Children was conducted with mothers only when children were 3 and 5 years of age.

The sample for this study was selected based on whether the biological father was residing in the home at the time of the 3-year In-Home interview $(n=1414)$. Families were excluded from analyses if the father did not provide key demographic information at baseline $(n=120)$; the father did not provide psychosocial information (e.g., depression, substance use, and father involvement) at 3 years ( $n=73$ ); the mother did not provide information on measures of child maltreatment at 3 years $(n=30)$; and the mother did not provide information on child aggression at 5 years $(n=234)$ - commonly because she did not participate in this wave of data collection. Missing data on other study variables $(n=34)$ resulted in a final sample of 923 families. Because non-marital births were oversampled at baseline, many fathers were not living in the home when the child was 3 years old. Therefore, when analyzing data from mothers and fathers together, a substantial decline is visible from the original cohort to the year-3 interview (Reichman et al., 2001).

\subsection{Measures}

Mothers and fathers reported on their own use of spanking. Maternal reports provided data for instances of both maternal and paternal psychological and physical child maltreatment (besides spanking) and the children's aggressive behavior. Although fathers self-reported their own use of spanking, fathers were not asked questions about 
Table 1

Sample demographic statistics, by level of combined parental spanking, $n=923$.

\begin{tabular}{|c|c|c|c|c|c|}
\hline Variable (M (SD) or \%) & Total sample & $\begin{array}{l}\text { No spanking } \\
(32 \%)\end{array}$ & $\begin{array}{l}\text { Either parent } 1-2 \\
\text { times }(24 \%)\end{array}$ & $\begin{array}{l}\text { Both parents } \\
1-2 \text { times (or) one } \\
\text { parent }>2 \text { times ( } 35 \% \text { ) }\end{array}$ & $\begin{array}{l}\text { Both parents }>2 \\
\text { times }(9 \%)\end{array}$ \\
\hline Higher child aggressive behavior age 5 , \% yes & 49 & $40 * * *$ & $49 * * *$ & $54 * * *$ & $63 * * *$ \\
\hline Higher child aggressive behavior age 3 , \% yes & 55 & $44^{* * *}$ & $60^{* * *}$ & $60^{* * *}$ & $63^{* * *}$ \\
\hline \multicolumn{6}{|l|}{ Paternal parenting risks } \\
\hline $\begin{array}{l}\text { Paternal psychological maltreatment of child, no. of incidents in prior } \\
\text { year (range: } 0-83 \text { incidents) }\end{array}$ & $17.2(17.1)$ & $10.1(13.3)^{* * *}$ & $15.9(15.7)^{* * *}$ & $21.8(17.8)^{* * *}$ & $27.5(18.8)^{* * *}$ \\
\hline $\begin{array}{l}\text { Paternal physical maltreatment of child, no. of incidents in prior year } \\
\text { (range: } 0-54 \text { incidents) }\end{array}$ & $4.7(8.7)$ & $2.0(5.4)^{* * *}$ & $2.7(4.9)^{* * *}$ & $7.0(9.9)^{* * * *}$ & $11.2(14.0)^{* * *}$ \\
\hline Paternal parenting stress (range: $1-4$ ) & $2.08(0.67)$ & $2.03(0.69)^{* * *}$ & $2.07(0.65)^{* * *}$ & $2.09(0.65)^{* * *}$ & $2.27(0.64)^{* * *}$ \\
\hline Paternal major depression, \% yes & 10 & 9 & 7 & 13 & 12 \\
\hline Paternal high alcohol use ( 4 or more drinks in 1 day in past year), \% yes & 30 & 27 & 28 & 33 & 32 \\
\hline Paternal use of drugs, $\%$ yes & 10 & 8 & 10 & 10 & 17 \\
\hline Father involvement with child (range: 0.54-6.85) & $4.5(1.1)$ & $4.6(1.1)$ & $4.5(1.1)$ & $4.5(1.0)$ & $4.4(1.0)$ \\
\hline \multicolumn{6}{|l|}{ Maternal parenting risks } \\
\hline $\begin{array}{l}\text { Maternal psychological maltreatment of child, no. of incidents in prior year } \\
\text { (range: } 0-102 \text { incidents) }\end{array}$ & $24.4(18.6)$ & $16.3(15.7)^{*}$ & $24.3(18.6)^{*}$ & $29.1(18.4)^{*}$ & $34.6(17.5)^{*}$ \\
\hline $\begin{array}{l}\text { Maternal physical maltreatment of child, no. of incidents in prior year } \\
\text { (range: } 0-57 \text { incidents) }\end{array}$ & $7.4(10.9)$ & $2.7(6.0)^{* * *}$ & $5.5(7.7)^{* * *}$ & $11.1(12.7)^{* * *}$ & $14.5(14.5)^{* * *}$ \\
\hline Maternal parenting stress (range: $1-4$ ) & $2.23(0.63)$ & $2.13(0.65)^{* * *}$ & $2.19(0.62)^{* * *}$ & $2.31(0.61)^{* * *}$ & $2.35(0.59)^{* * *}$ \\
\hline Maternal major depression, \% yes & 16 & $10^{* *}$ & $19^{* *}$ & $19^{* *}$ & $20 * *$ \\
\hline Maternal high alcohol use ( 4 or more drinks in 1 day in past year), \% yes & 10 & 10 & 10 & 10 & 13 \\
\hline Maternal use of drugs, \% yes & 6 & $3 * *$ & $5^{* *}$ & $10^{* *}$ & $7 * *$ \\
\hline Mother victim of intimate partner aggression and/or violence, \% yes & 43 & $35^{*}$ & $48^{*}$ & $46^{*}$ & $48^{*}$ \\
\hline \multicolumn{6}{|l|}{ Demographic and household characteristics } \\
\hline Male child, \% & 50 & $45^{*}$ & $50^{*}$ & $53^{*}$ & $62 *$ \\
\hline Child daily exposure to TV (range: $0-16.86 \mathrm{~h}$ per day) & $3.0(2.1)$ & $2.5(1.9)^{* * *}$ & $3.0(2.1)^{* * *}$ & $3.2(2.0)^{* * *}$ & $3.6(2.4)^{* * *}$ \\
\hline Mother's age, median, years (range: $15-44 y$ ) & $26.7(6.1)$ & $27.9(6.0)^{* *}$ & $26.6(6.3)^{* *}$ & $25.8(6.0)^{* *}$ & $26.0(5.9)^{* *}$ \\
\hline Mother's education: Less than high school, \% & 24 & $26 *$ & $24^{*}$ & $23 *$ & $18^{*}$ \\
\hline High school & 28 & 22 & 32 & 29 & 31 \\
\hline Some college & 28 & 24 & 28 & 29 & 32 \\
\hline College graduate & 21 & 28 & 17 & 19 & 20 \\
\hline Mother's race/ethnicity: White, \% & 34 & $37 * * *$ & $33 * * *$ & $29 * * *$ & $45^{* * *}$ \\
\hline African American & 34 & 21 & 35 & 45 & 39 \\
\hline Hispanic & 27 & 37 & 30 & 21 & 11 \\
\hline Other & 5 & 6 & 2 & 5 & 5 \\
\hline Mother foreign-born, \% & 16 & $26^{* * *}$ & $18^{* * *}$ & $10^{* * *}$ & $4^{* * *}$ \\
\hline Annual household income (range: 1-1000) & $\begin{array}{l}52,239 \\
(60,514)\end{array}$ & $\begin{array}{l}59,726 \\
(63,985)^{*}\end{array}$ & $53,073(74,728) *$ & $45,799(49,768)^{*}$ & $\begin{array}{l}48,851 \\
(37,837)^{*}\end{array}$ \\
\hline Father's age, median, years (range: 16-61) & $29.1(7.0)$ & $30.6(7.2)^{* * *}$ & $29.5(7.2)^{* * *}$ & $27.9(6.6)^{* * *}$ & $28.2(6.2)^{* * *}$ \\
\hline Father's education: Less than high school, \% & 25 & $26 * *$ & $28^{* *}$ & $24^{* *}$ & $18^{* *}$ \\
\hline High school or equivalent & 29 & 24 & 29 & 32 & 29 \\
\hline Some college & 27 & 22 & 26 & 29 & 35 \\
\hline College graduate & 20 & 28 & 18 & 14 & 17 \\
\hline Father's race/ethnicity: White, \% & 33 & $37 * * *$ & $29^{* * *}$ & $29 * * *$ & $42^{* * *}$ \\
\hline African American & 37 & 22 & 37 & 48 & 48 \\
\hline Hispanic & 26 & 34 & 33 & 20 & 8 \\
\hline Other & 4 & 6 & 2 & 4 & 2 \\
\hline Father foreign-born, \% & 16 & $27 * * *$ & $17 * * *$ & $9 * * *$ & $2^{* * *}$ \\
\hline
\end{tabular}

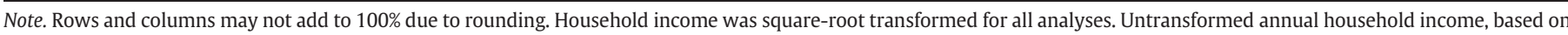

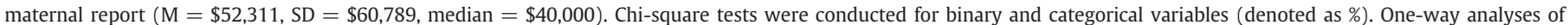
variance (ANOVA) were conducted for continuous variables. Results are reported for the omnibus test.

$* * * \mathrm{p}<.001$.

** $\mathrm{p}<.01$.

* $\mathrm{p}<.05$.

other forms of psychological and physical maltreatment and thus we relied on maternal reports of these behaviors. Descriptive statistics for all study variables are presented in Table 1 .

\subsubsection{Predictor variable: Spanking of the child at 3 years of age}

In separate 3-year core interviews, mothers and fathers indicated whether they had spanked the child in the past month when he or she was misbehaving or acting up. If so, they indicated the frequency of spanking: never (coded 0 ), 1-2 times (coded 1 ), or $>2$ times (coded 2). Mother and father spanking variables were coded into separate variables. A third variable indicated the child's combined exposure to spanking by both mother and father at 3 years of age. Approximately one third of children $(32 \%)$ were spanked by neither parent in the past month (coded 0); almost one quarter (24\%) were spanked 1-2 times by either their mother or father, but not both (coded 1 ); $35 \%$ were spanked $>2$ times by one parent or spanked 1-2 times by both parents (coded 2); and in $9 \%$ of cases, the child was spanked $>2$ times by both parents (coded 3 ).

\subsubsection{Dependent variable: Child aggression at age 5}

Twelve items from the aggression subscale of the Child Behavior Checklist for age 5 (Achenbach \& Rescorla, 2000) measured whether ( $0=$ not true, $1=$ somewhat or sometimes true, $2=$ very true or often true) the child argues a lot; is cruel; bullies and shows meanness to others; destroys (his or her) own things; destroys things belonging to family or others; is disobedient at home; is disobedient at school or in childcare; gets in many fights; physically attacks people; screams a lot; teases a lot; threatens people; or is unusually loud $(\alpha=0.71$; mean $=0.36$, median $=0.25$, standard deviation $=$ $0.30)$. Because the variable was highly skewed, we followed the 
precedent set forth in prior research (e.g., Taylor, Manganello, et al., 2010) and dichotomized at the median value and analyzed as lower aggression (scores of $0-0.25$ ) versus higher aggression (scores of 0.26-1.58). The FFCWS did not use all items from the CBCL aggression subscale; therefore it is not possible to calculate meaningful clinical cut-points using the current dataset.

\subsubsection{Child aggression at age 3}

Nineteen items from the aggression subscale of the Child Behavior Checklist for age 3 (Achenbach \& Rescorla, 2000) measured whether $(0=$ not true, $1=$ somewhat or sometimes true, $2=$ very true or often true) the child is defiant; has demands that must be met immediately; is disobedient; does not seem to feel guilty after misbehaving; is easily frustrated; gets in many fights; hits others; has angry moods; punishment does not change behavior; screams a lot; is selfish or will not share; is stubborn, sullen, or irritable; has temper tantrums or hot temper; is uncooperative; wants a lot of attention; cannot stand waiting and wants everything now; destroys things belonging to family members or other children; hurts animals or people without meaning to; or physically attacks people $(\alpha=$ 0.87 ; mean $=0.58$, median $=0.526$, standard deviation $=0.33$ ) This variable was also dichotomized at the median value and analyzed as lower aggression (scores of $0-0.525$ ) versus higher aggression (scores of $0.526-1.95$ ).

\subsection{Possible confounds}

We assessed numerous self-reported parenting risk factors that might confound the relationship between spanking and child aggression. All parenting risk factors were assessed as control variables where children were 3 years of age. Such factors include physical and psychological maltreatment of the child, intimate partner aggression and violence, parental stress, and alcohol use, all of which have been linked with spanking (Black et al., 2001; Lee, Altschul, Shair, \& Taylor, 2011a,b; Lee et al., 2011b; Slep \& O'Leary, 2005; Taylor, Lee, et al., 2010; Taylor, Manganello, et al., 2010; Zolotor et al., 2008) as well as with childhood aggression (Brennan et al., 2003; Koblinsky et al., 2006; McFarlane et al., 2003; Meadows et al., 2007; Owens \& Shaw, 2003). Child's daily television viewing also was included, given its relationship to child aggression (Manganello \& Taylor, 2009).

\subsubsection{Child maltreatment}

Seven items from the Parent-Child Conflict Tactics Scales (CTSPC) assessed frequency of father-to-child and mother-to-child psychological and physical maltreatment at age 3 (Straus, Hamby, Finkelhor, Moore, \& Runyan, 1998). An item measuring spanking was excluded from the physical aggression subscale to avoid overlap with the key independent variable in this study. Though the CTSPC subscales are often referred to as measuring parental aggression, we use the term maltreatment so that we do not confuse parent-to-child aggression with the outcome variable of child aggressive behavior. We also use the term maltreatment because parental behaviors such as shaking a child meet most states' legal definition of maltreatment. The CTSPC asks parents to recall and report both the incidence and frequency of a range of physical aggression (e.g., shook child and slapped child) and psychological aggression (e.g., shouted, yelled, or screamed at, and threatened to spank or hit but did not actually do it) (Straus et al., 1998). Behaviors such as shaking and, hitting, or slapping a child with an object (and leaving bruises) would meet the criteria of child maltreatment.

\subsubsection{Father-to-mother intimate partner aggression and violence}

Mothers reported physical or psychological aggression from her spouse or current partner. Three items (e.g., "He slaps or kicks you") from the Conflict Tactics Scale (Straus, Hamby, Boney-McCoy, \& Sugarman, 1996) assessed physical aggression, and four items adapted from the Spouse Observation Checklist (Lloyd, 1996; Weiss \& Margolin, 1977) assessed psychological aggression (e.g., "He tries to keep you from seeing or talking with your friends or family"). This variable was dichotomized for analysis (none versus any).

\subsubsection{Parenting risks}

Parents self-reported their level of parenting stress using items from the Personal Distress subscale of the Parenting Stress Index Short Form by indicating their agreement $(1=$ strongly disagree to $4=$ strongly agree) with four items including, "Being a parent is harder than I thought it would be" and "I feel trapped by my responsibilities as a parent" $\left(\alpha_{\text {mother }}=0.60 ; \alpha_{\text {father }}=0.63\right)$.

Mothers and fathers self-reported depression using the Composite International Diagnostic Interview - Short Form (CIDI-SF), Section A (Kessler, Andrews, Mroczek, Ustun, \& Wittchen, 1998). The CIDI-SF is a standardized instrument that uses the criteria set forth in the Diagnostic and Statistical Manual of Mental Disorders (DSM-IV) to determine the probability that the respondent would be diagnosed with major depression if given the full CIDI interview. Major depression is indicated by self-report of feelings of depression or anhedonia experienced for most of the day, every day, for at least 2 weeks. In the current study, participants were classified as likely to have major depression if they endorsed the screening items and 3 or more depressive symptoms (e.g., losing interest, feeling tired, and change in weight) $(0=$ no, $1=$ yes $)$.

Mothers and fathers self-reported alcohol use and drug use. A dichotomous variable was created to indicate high alcohol use by assessing whether the father or mother had consumed $\geq 4$ drinks in 1 day in the past 12 months $(0=$ consumed $0-3$ drinks in 1 day in the past year or $1=$ consumed $\geq 4$ drinks in 1 day in the past year). The FFCWS alcohol use questions are based on the CIDI-SF alcohol-dependence questions, which are intended to indicate the probability or likelihood that the respondent would receive a diagnosis of alcohol dependent had they received the full CIDI. However, few men or women met the CIDI-SF criteria indicating probability of alcohol dependence. Therefore, we created a variable to indicate "high alcohol use." Though less stringent than the CIDI-SF, our operationalization of high alcohol use approximates the National Institute on Alcohol and Alcoholism's definition of a "heavy drinking day," as indicated by $\geq 5$ drinks in a single day for men and $\geq 4$ drinks in a single day for women (National Institute on Alcohol Abuse and Alcoholism, 2005). We also assessed any drug use in the past year $(0=$ no, $1=$ yes $)$.

Fathers self-reported their daily involvement with the child, measured with a mean score of the number of days in a week the father provided 13 different types of care to the child, among them: sings songs or nursery rhymes with child, hugs or shows physical affection to child, tells child that he loves him or her, reads stories to child, assists child with eating, and puts child to bed ( $\alpha=.86$ ). Parenting stress and father involvement with the child were analyzed as continuous variables. The other parenting risk variables were dichotomized (no versus yes).

\subsubsection{Demographic and household characteristics}

Household and demographic characteristics include parental age, race/ethnicity, education level, and household income. We assessed foreign birth or nativity status because prior studies show that immigrant mothers and fathers may less frequently engage in harsh punishment of young children when compared to native-born American parents (Altschul \& Lee, 2011; Lee et al., 2011; Taylor, Guterman, Lee, \& Rathouz, 2009). We assessed child characteristics, including the child's sex (Gershoff, 2002), and the child's exposure to television (Manganello \& Taylor, 2009) - which we measured with two questions asking mothers to estimate how many hours the child spent watching TV or videos at home or elsewhere on weekdays and weekend days. 


\subsection{Statistical analysis}

First, we examined descriptive statistics and carried out bivariate analyses (ANOVA and $\chi^{2}$ ) to assess differences in all study variables as a function of combined parental spanking; results are presented in Table 1. Second, we used logistic regression to examine relationships between maternal and paternal spanking when the child was 3 years old and child aggression at age 5 . Three models were examined for maternal spanking, paternal spanking, and combined maternal and paternal spanking. Model 1 examined the association of spanking the child at age 3 and child aggression at age 5; Model 2 controlled for the child's initial level of aggression at age 3; and Model 3 added psychosocial parenting risk factors and demographic characteristics. Model 3 for the combined effects of maternal and paternal spanking included only maternal education and race/ethnicity. For example, $88 \%$ of parents were of the same race/ethnicity. Therefore including both maternal and paternal reports was unnecessary and increased the risk of multicollinearity in the models. Furthermore, these variables were not central to the primary research questions examined in this study and were used only as controls. Annual household income was log transformed in all analyses, and logistic regression models were adjusted for city of the 3-year interview and parental marital status at birth - two important aspects of the FFCWS sampling design.

To be thorough and as a check for the robustness of our results, we compared the logistic regression models reported below to ordinary least squares regression models, with child aggression at age 5 analyzed as a continuous variable and transformed to minimize skew. The pattern of associations between spanking and child aggression were the same as those observed in the logistic regression models. Therefore, for ease of interpretation and to maintain consistency with prior work (Taylor, Manganello, et al., 2010), we report the logistic regression results herein.

\section{Results}

Table 1 presents overall study descriptive statistics as well as bivariate results for parenting risks and demographic and household features as a function of combined parental spanking. Many of these variables were significantly associated with greater parental spanking, in the expected direction. For example, consistent with a study examining maternal spanking and child aggression (Taylor, Manganello, et al., 2010), factors such as maternal and paternal major depression and child maltreatment were associated with higher levels of parental spanking.

Adjusted odds ratios (AOR) and 95\% confidence intervals (CI) for logistic regression analyses examining maternal and paternal spanking are presented in Tables 2 and 3, respectively. Parents who did not spank are the comparison group in each case. As Table 2, Model 1 illustrates, mothers' use of spanking (more than 2 times in the preceding month) when the child was age 3 is associated with more than double the odds of increased child aggressive behavior at age 5 when compared to the reference group (no maternal spanking in the preceding month). In Model 2, after controlling for child's level of aggression at age 3, the odds of increased child aggression were lower than in Model 1, as anticipated. However, frequent spanking was still associated with nearly double the odds of increased aggression by age 5 . As shown in Model 3 , adding maternal parenting risk and demographic features did not greatly change this relationship. When compared to the no-spanking group, mothers' use of spanking more than 2 times in the preceding month was still associated with nearly double the odds of increased subsequent aggression (AOR: 1.67 [CI: 1.10-2.55]).

Similarly, as seen in Table 3, Model 1, when compared to the reference group of no paternal spanking in the past month, fathers' use of frequent spanking (more than 2 times in the past month) with the child at age 3 was also associated with nearly double the odds of high child aggression at age 5. Model 2, after controlling for the child's level of aggression at age 3, demonstrated only a small decrease from Model 1 in the AOR for fathers' use of spanking more than 2 times. In Model 3, after adding paternal demographic and parenting risks, the association changed little from the two prior models; paternal spanking $>2$ times was associated with increased child aggression at age 5 (AOR: 1.59 [CI: 1.09-2.32]).

Table 4 presents results examining the combined influence of paternal and maternal spanking on 3-year-olds as a predictor of children's aggression at age 5 . Similar to Tables 2 and 3, the reference group for all statistical models is no parental spanking (by either mother or father) in the preceding month. The AORs presented in Model 1 demonstrate that, as frequency of parental spanking increased, so did the odds of high child aggression at age 5. In Model 2, after controlling for child's level of aggressive behavior at age 3 , AORs were reduced as anticipated; however, the same dose-response pattern exhibited in Model 1 remained. Model 3, compared to Model 2 , evidenced only minor changes in the associated AORs. This final model indicated that, compared to children who were not spanked at all, children who were spanked more than 2 times by one parent (or 1-2 times by both parents) in the prior month had higher odds of increased aggression (AOR: 1.40 [CI: 1.05-1.86]), as did children spanked more than 2 times by both parents (AOR: 2.01 [CI: 1.033.94]).

\section{Discussion}

In the current study, the more frequently young children were spanked-regardless of whether mother, father, or both administered the punishment-the higher their odds of increased aggressive behavior two years later. The importance of these associations is underscored by the fact that selection of fathers living in the same household as their children biased the sample toward more advantaged families (Carlson \& McLanahan, 2010; Guzzo \& Lee, 2008). In general, we would expect lower levels of aggression among children in two-parent families (Sourander \& Helstelä, 2005). Indeed this is the case when we compare the mean and range of aggressive behavior of the subgroup of children used for this study (mean $=0.36$, median $=0.25$, standard deviation $=0.30$ ) to the subgroup of children used in a prior study of maternal spanking that included both single- and two-parent families (mean: 0.40; median: 0.33; SD: 0.33) (Taylor, Manganello, et al., 2010). Yet, even in the current sample of children with comparatively lower levels of aggressive behavior, 3-year-olds who were spanked more than 2 times by at least one parent, or 1-2 times by both parents-as $44 \%$ of the children in this study had experienced in the month prior to data collection-were more likely to display increased child aggression two years later.

One limitation of prior research is its failure to examine fathers' parenting behaviors. Results of this study indicate that fathers have an important influence on the development of child aggression. Results also point to spanking by fathers being as harmful to children as spanking by mothers. Meaningful quantitative or qualitative differences in the associations of maternal versus paternal spanking and child aggression do not appear to exist (Martin et al., 2007; Prinzie et al., 2006). The pattern of findings and the associated AORs for fathers as observed in this study were similar to analyses reported previously with a larger sample of mothers (Taylor, Manganello, et al., 2010). The similarity in patterns of odds ratios that linked maternal and paternal spanking to child aggression may suggest that young children do not attribute different meaning to spanking when the mother or the father spanks (Prinzie et al., 2006).

Consistent with social learning theory (Bandura, 1973), results of this study suggest that parental spanking reinforces the child's use of aggression. Regardless of whether the mother, the father, or both parents used physical discipline, spanking may increase the negative child behaviors that parents initially sought to extinguish with 
Table 2

AORs of maternal factors at age 3 predicting higher levels of child aggression at age $5, n=923$.

\begin{tabular}{|c|c|c|c|c|c|c|}
\hline \multirow[t]{2}{*}{ Variable } & \multicolumn{2}{|l|}{ Model 1} & \multicolumn{2}{|l|}{ Model 2} & \multicolumn{2}{|l|}{ Model 3} \\
\hline & AOR $(95 \% \mathrm{CI})$ & $P$ value & AOR $(95 \% \mathrm{CI})$ & $P$ value & AOR $(95 \% \mathrm{CI})$ & $P$ value \\
\hline \multicolumn{7}{|l|}{ Maternal spanking ${ }^{\mathrm{a}}$} \\
\hline$>2$ times in past month & $2.11(1.46-3.04)$ & $<.001$ & $1.79(1.22-2.62)$ & $<.01$ & $1.67(1.10-2.55)$ & $<.01$ \\
\hline $1-2$ times in past month & $1.22(0.95-1.57)$ & .12 & $1.10(0.83-1.44)$ & .52 & $1.12(0.86-1.45)$ & .39 \\
\hline Child aggressive behavior, age 3 & & & $3.61(2.94-4.44)$ & $<.001$ & $3.33(2.59-4.29)$ & $<.001$ \\
\hline \multicolumn{7}{|l|}{ Maternal parenting risks } \\
\hline Maternal psychological maltreatment of child & & & & & $1.01(0.99-1.02)$ & .30 \\
\hline Maternal physical maltreatment of child (spanking not included) & & & & & $1.00(0.99-1.01)$ & .99 \\
\hline Maternal parenting stress & & & & & $1.25(1.07-1.47)$ & $<.01$ \\
\hline Maternal major depression & & & & & $0.82(0.54-1.24)$ & .35 \\
\hline Maternal high alcohol use ( 4 or more drinks in one day in past year) & & & & & $1.25(0.69-2.29)$ & .46 \\
\hline Maternal use of drugs & & & & & $1.08(0.65-1.77)$ & .77 \\
\hline Mother victim of intimate partner aggression and/or violence & & & & & $1.12(0.88-1.43)$ & .34 \\
\hline \multicolumn{7}{|l|}{ Demographic and household characteristics } \\
\hline Male child & & & & & $1.35(0.94-1.95)$ & .11 \\
\hline Child daily exposure to TV & & & & & $1.01(0.96-1.05)$ & .78 \\
\hline Mother's age & & & & & $1.02(0.99-1.05)$ & .19 \\
\hline \multicolumn{7}{|l|}{ Mother's education level } \\
\hline Less than high school degree & & & & & 1 [Reference] & \\
\hline High school or equivalent & & & & & $1.43(0.92-2.22)$ & .11 \\
\hline Some college & & & & & $0.99(0.98-1.44)$ & .96 \\
\hline College graduate & & & & & $0.86(0.49-1.51)$ & .61 \\
\hline \multicolumn{7}{|l|}{ Mother's race/ethnicity } \\
\hline White & & & & & 1 [Reference] & \\
\hline African American & & & & & $0.65(0.45-0.93)$ & $<.05$ \\
\hline Hispanic & & & & & $1.00(0.65-1.55)$ & .99 \\
\hline Other & & & & & $1.18(0.70-1.99)$ & .55 \\
\hline Mother foreign-born (yes) & & & & & $1.15(0.72-1.84)$ & .56 \\
\hline Annual household income & & & & & $1.00(1.00-1.00)$ & .13 \\
\hline
\end{tabular}

Abbreviations: AOR indicates adjusted odds ratio; $\mathrm{CI}$, confidence interval.

Note: All models were adjusted for two key selection variables in the FFCWS: marital birth and city.

a Reference group is no spanking.

Table 3

AORs of paternal factors at age 3 predicting higher levels of child aggression at age $5, n=923$.

\begin{tabular}{|c|c|c|c|c|c|c|}
\hline \multirow[t]{2}{*}{ Variable } & \multicolumn{2}{|l|}{ Model 1} & \multicolumn{2}{|l|}{ Model 2} & \multicolumn{2}{|l|}{ Model 3} \\
\hline & OR $(95 \% \mathrm{CI})$ & $P$ value & OR $(95 \% \mathrm{CI})$ & $P$ value & OR $(95 \% \mathrm{CI})$ & $P$ value \\
\hline \multicolumn{7}{|l|}{ Paternal spanking at age $3^{\mathrm{a}}$} \\
\hline$>2$ times in past month & $1.71(1.27-2.31)$ & $<.001$ & $1.62(1.11-2.37)$ & $<.05$ & $1.59(1.09-2.32)$ & $<.05$ \\
\hline $1-2$ times in past month & $1.32(1.06-1.64)$ & $<.05$ & $1.15(0.91-1.45)$ & .41 & $1.16(0.89-1.51)$ & .28 \\
\hline Child aggressive behavior, age 3 & & & $3.73(3.06-4.55)$ & $<.001$ & $3.44(2.85-4.14)$ & $<.001$ \\
\hline \multicolumn{7}{|l|}{ Paternal parenting risks } \\
\hline Paternal psychological maltreatment of child & & & & & $1.01(1.00-1.02)$ & .08 \\
\hline Paternal physical maltreatment of child (spanking not included) & & & & & $1.00(0.98-1.03)$ & .69 \\
\hline Paternal parenting stress & & & & & $1.03(0.73-1.45)$ & .88 \\
\hline Paternal major depression & & & & & $1.24(0.61-2.54)$ & .55 \\
\hline Paternal high alcohol use ( 4 or more drinks in one day in past year) & & & & & $1.30(0.90-1.90)$ & .17 \\
\hline Paternal use of drugs & & & & & $0.79(0.44-1.41)$ & .42 \\
\hline Father involvement with child & & & & & $0.98(0.85-1.12)$ & .76 \\
\hline \multicolumn{7}{|l|}{ Demographic and household characteristics } \\
\hline Male child & & & & & $1.32(0.95-1.85)$ & .10 \\
\hline Child daily exposure to TV & & & & & $1.00(0.95-1.06)$ & .87 \\
\hline Father's age & & & & & $1.01(0.99-1.03)$ & .35 \\
\hline \multicolumn{7}{|l|}{ Father's education } \\
\hline Less than high school degree & & & & & 1 [Reference] & \\
\hline High school or equivalent & & & & & $0.75(0.54-1.04)$ & .08 \\
\hline Some college & & & & & $0.86(0.38-0.82)$ & $<.01$ \\
\hline College graduate & & & & & $0.40(0.23-0.69)$ & $<.01$ \\
\hline \multicolumn{7}{|l|}{ Father's race/ethnicity } \\
\hline White & & & & & 1 [Reference] & \\
\hline African American & & & & & $0.63(0.42-0.93)$ & $<.05$ \\
\hline Hispanic & & & & & $0.84(0.62-1.13)$ & .25 \\
\hline Other & & & & & $1.94(0.78-4.82)$ & .15 \\
\hline Father foreign-born & & & & & $1.25(0.82-1.91)$ & .30 \\
\hline Annual household income & & & & & $1.00(1.00-1.00)$ & .27 \\
\hline
\end{tabular}

Abbreviations: AOR indicates adjusted odds ratio; $\mathrm{CI}$, confidence interval.

Note: All models were adjusted for two key selection variables in the FFCWS: marital birth and city.

a Reference group is no spanking. 
Table 4

AORs of paternal and maternal factors at age 3 predicting higher levels of child aggression at age 5, $n=923$.

\begin{tabular}{|c|c|c|c|c|c|c|}
\hline \multirow[t]{2}{*}{ Variable } & \multicolumn{2}{|l|}{ Model 1} & \multicolumn{2}{|l|}{ Model 2} & \multicolumn{2}{|l|}{ Model 3} \\
\hline & $\operatorname{AOR}(95 \% \mathrm{CI})$ & $P$ value & AOR $(95 \% \mathrm{CI})$ & $P$ value & AOR $(95 \% \mathrm{CI})$ & $P$ value \\
\hline \multicolumn{7}{|l|}{ Parental spanking at age $3^{\mathrm{a}}$} \\
\hline Both parents, $>2$ times $^{\mathrm{b}}$ & $2.60(1.59-4.23)$ & $<.001$ & $2.19(1.20-4.00)$ & $<.01$ & $2.01(1.03-3.94)$ & $<.05$ \\
\hline Both parents $1-2$ times or one parent $>2$ times $^{c}$ & $1.72(1.37-2.16)$ & $<.001$ & $1.49(1.12-1.98)$ & $<.01$ & $1.40(1.05-1.86)$ & $<.05$ \\
\hline One parent, $1-2$ times $^{\mathrm{d}}$ & $1.37(1.01-1.88)$ & $<.05$ & $1.16(0.84-1.60)$ & .38 & $1.15(0.81-1.64)$ & .42 \\
\hline Child aggressive behavior, age 3 & & & $3.64(2.94-4.49)$ & $<.001$ & $3.33(2.60-4.27)$ & $<.001$ \\
\hline \multicolumn{7}{|l|}{ Maternal parenting risks } \\
\hline Maternal psychological maltreatment of child & & & & & $1.00(0.99-1.01)$ & .71 \\
\hline Maternal physical maltreatment of child (spanking not included) & & & & & $1.00(0.99-1.02)$ & .81 \\
\hline Maternal parenting stress & & & & & $1.28(1.07-1.52)$ & $<.01$ \\
\hline Maternal major depression & & & & & $0.79(0.51-1.24)$ & .31 \\
\hline Maternal high alcohol use ( 4 or more drinks in one day in past year) & & & & & $1.21(0.66-2.24)$ & .54 \\
\hline Maternal use of drugs & & & & & $1.11(0.71-1.74)$ & .65 \\
\hline Mother victim of intimate partner aggression and/or violence & & & & & $1.10(0.85-1.42)$ & .46 \\
\hline \multicolumn{7}{|l|}{ Paternal parenting risks } \\
\hline Paternal psychological maltreatment of child & & & & & $1.01(0.99-1.02)$ & .34 \\
\hline Paternal physical maltreatment of child (spanking not included) & & & & & $1.00(0.98-1.02)$ & .98 \\
\hline Paternal parenting stress & & & & & $1.01(0.72-1.43)$ & .94 \\
\hline Paternal major depression & & & & & $1.35(0.67-2.71)$ & .40 \\
\hline Paternal high alcohol use ( 4 or more drinks in one day in past year) & & & & & $1.21(0.86-1.71)$ & .27 \\
\hline Paternal use of drugs & & & & & $0.85(0.47-1.54)$ & .59 \\
\hline Father involvement with child & & & & & $1.00(0.86-1.14)$ & .94 \\
\hline \multicolumn{7}{|l|}{ Demographic and household characteristics } \\
\hline Male child & & & & & $1.32(0.92-1.89)$ & .13 \\
\hline Child daily exposure to TV & & & & & $1.00(0.95-1.05)$ & .95 \\
\hline Mother's age & & & & & $1.04(1.00-1.09)$ & .07 \\
\hline Father's age & & & & & $0.98(0.95-1.00)$ & .11 \\
\hline \multicolumn{7}{|l|}{ Mother's education } \\
\hline Less than high school degree & & & & & 1 [Reference] & \\
\hline High school or equivalent & & & & & $1.40(0.92-2.13)$ & .12 \\
\hline Some college & & & & & $0.97(0.69-1.37)$ & .87 \\
\hline College graduate & & & & & $0.83(0.51-1.35)$ & .46 \\
\hline \multicolumn{7}{|l|}{ Mother's race/ethnicity } \\
\hline White & & & & & 1 [Reference] & \\
\hline African American & & & & & $0.67(0.47-0.95)$ & $<.05$ \\
\hline Hispanic & & & & & $1.00(0.63-1.58)$ & .99 \\
\hline Other & & & & & $1.14(0.69-1.89)$ & .61 \\
\hline Mother foreign-born & & & & & $1.14(0.61-2.12)$ & 69 \\
\hline Father foreign-born & & & & & $1.17(0.76-1.81)$ & .47 \\
\hline Annual household income & & & & & $1.00(1.00-1.01)$ & .15 \\
\hline
\end{tabular}

Abbreviations: AOR indicates adjusted odds ratio; $\mathrm{Cl}$, confidence interval.

Note: All models were adjusted for two key selection variables in the FFCWS: marital birth and city.

${ }^{a}$ Reference group is no spanking from either parent in the past month (coded 0 ).

b Both parents spanked $>2$ times (coded 3 ).

c Both parents spanked 1-2 times (or) spanked $>2$ times by one parent (coded 2).

${ }^{\mathrm{d}}$ One parent spanked 1-2 times and other parent spanked 0 times (coded 1 ).

discipline. A common critique of studies of spanking is that most fail to control for the child's exposure to other forms of more serious punishment and/or physical maltreatment. The current study included comprehensive variables assessing parenting risk factors, including the child's exposure to more serious forms of harsh punishment assessed using the CTSPC, a valid and reliable proxy measure for child maltreatment. Neither controlling for exposure to punishment indicative of maltreatment nor accounting for aggressive child behavior at age 3 fundamentally changed the relationship between spanking and child aggression. The dose-response association means that children are at risk of being negatively affected by exposure to high levels of physical discipline even if one caregiver never spanks.

\subsection{Implications for intervention}

Although controversy remains as to the magnitude and extent of negative effects of spanking on children, many professional organizations concerned with children's wellbeing, such as the American Academy of Pediatrics and the National Association of Pediatric Nurse Practitioners, recommend that parents avoid spanking their children and instead use alternative forms of discipline. Such policies appear grounded in the precautionary principle, citing that the bulk of the evidence links spanking with risk of harm to children, the lack of evidence indicating that spanking is necessary or beneficial in order to attain positive and desired results in children, and the existence of many non-physical forms of punishment available to parents to promote positive behavior and manage difficult behavior in children (e.g., Durrant, 2007).

This present study contributes to a growing body of research regarding the negative consequences of spanking and highlights the need to ensure that parent education programs address the important topic of parental spanking with specific prohibitions against its use. The estimates linking spanking to child aggression demonstrate a substantively small effect overall. Yet, in the context of a behavior that is frequently practiced by many parents (e.g., in this study based on parental self-report, $44 \%$ of the 3 -year-olds were spanked at least 2 times in the past month by either or both parents), even a relatively small change in behavior, such as reducing or eliminating spanking, potentially affects a large number of children and thus may have an important impact. 
A recent overview suggests that the majority of universal parenting programs explicitly discourage the use of corporal punishment and recommend alternatives, albeit some of these programs only mention or address spanking in passing (Voisine \& Baker, 2012). Even so, empirical data would suggest that this message is not effectively reaching American parents. In one study, $25 \%$ of respondents indicated support for the belief that spanking improves child behavior and $22 \%$ indicated that other forms of discipline are not as effective as spanking (Taylor, Al-Hiyari, Lee, Priebe, \& Wiggleton, 2013). Although spanking is a controversial and difficult topic to address, practitioners must provide parents with alternatives to spanking when seeking to correct their children's misbehavior.

In addition, this study underscores the importance of targeting parent education to fathers and men in roles (i.e., social fathers) where they are caring for young children. In general, very few parenting programs or interventions for families directly consider fathers. For example, a recent meta-analysis of 77 parent training programs indicated that only four focused on fathers (Kaminski et al., 2008). Some of the most commonly used parent intervention models, such as home visitation, are designed exclusively for mothers; this gap in services to fathers persists despite studies showing that effectiveness of such programs may be compromised when fathers are not included or when there is domestic violence in the home (Eckenrode et al., 2000). Fathers also seem less likely than mothers to participate actively in parenting programs. Only $17 \%$ of fathers participated in at least one parent education program, and fewer than $10 \%$ participated in father-only events (as opposed to events that involved mothers and fathers) offered through Early Head Start (Raikes, Summers, \& Roggman, 2005) and may benefit less from services, perhaps in part because parenting services are not targeted to their parenting needs (Lundahl, Tollefson, Risser, \& Lovejoy, 2008).

Another implication is the importance of early intervention with parents of young children, given numerous recent studies demonstrating that spanking negatively influences child wellbeing during the first five years of life (e.g., Berlin et al., 2009; Maguire-Jack et al., 2012; Taylor, Manganello, et al., 2010), even after taking into account potential moderators such as maternal warmth (Berlin et al., 2009; Lee, Altschul, \& Gershoff, in press) and cultural norms in parenting practices (Gershoff, Grogan-Kaylor, Lansford, Chang, Zelli, Deater-Deckard, et al., 2010). Perinatal clinical visits may be an important opportunity to screen for child aggression and frequent use of parental physical discipline. Prior research indicates that approximately $60 \%$ of pediatricians regularly screen parents for their use of aggression, and that most pediatricians are more likely to provide parents with alternative strategies (such as use of time out) rather than explicitly tell parents about the potential consequences associated with spanking young children (Scholer, Nix, \& Patterson, 2006). The prevalence of such behavior points to the importance of educating pediatricians and residents regarding research showing that spanking has the potential to harm children (Scholer, Brokish, Mukherjee, \& Gigante, 2008; Scholer et al., 2006).

\subsection{Study limitations and considerations for future research}

In the current study, mothers and fathers provided self-report of spanking toward their 3-year old child. Parents were not given a definition of spanking, so it is possible that for some parents this was selfdefined as a more extreme action than for others. Another limitation of the current study is that we did not attempt to assess the context in which spanking took place. For example, some researchers have suggested that maternal warmth (Deater-Deckard, Ivy, \& Petrill, 2006) or cultural context (Baumrind, Larzelere, \& Cowan, 2002; Benjet \& Kazdin, 2003) moderate the association between parental spanking and child aggression, while other researchers have failed to find such links (Gershoff et al., 2010; Lee et al., in press).
Although fathers self-reported their own use of spanking, fathers were not asked questions about other forms of psychological and physical maltreatment toward their child. Thus, we used maternal reports of these behaviors. Reliance on mothers' report of both children's aggressive behavior and fathers' physical and psychological child maltreatment may introduce some measurement bias. Prior research with the child maltreatment measures used in this study indicates that, in two-parent families, mothers are reliable and accurate reporters of the fathers' behavior toward their children (Lee, Lansford, Pettit, Bates, \& Dodge, 2012). There was a high correlation between maternal report of fathers' behavior and fathers' self-report. Mothers tended to slightly underreport fathers' physical and psychological maltreatment of the child (Lee et al., 2012). Despite these assurances regarding the reliability and generalizability of the child maltreatment measure used in this study it, as with all self-reported measures, should be viewed as a proxy for actual maltreatment. It is important to consider that all measures of parent-to-child aggression are likely to have some source of bias. For example, administrative records underestimate maltreatment and are plagued by bias and misclassification (Runyan, Cox, Dubowitz, et al., 2005). Furthermore, some have argued that measures of maltreatment that assess parental behaviors across multiple domains, such as the one used in this study, provide more reliable estimates of the number of children who are actually at risk for child maltreatment than are indicated by CPS substantiation rates (Straus et al., 1998).

The current study is further limited in that we lack the ability to compare the parenting practices of residential and nonresidential fathers, because comparable data on nonresidential fathers was not available for some measures. Future research should examine the role of nonresidential fathers in child discipline.

Finally, it may be useful in future research to capture greater variability in parental spanking. Parents who spank regularly may actually spank more than 2 times a month. It is also notable that the reliability coefficients for the parenting stress measure were quite low, probably because the scale included only 4 items. Although it would be useful to scrutinize spanking frequency in more detail, we were unable to do so in this study.

\section{Conclusions}

These findings suggest that educational efforts should continue to promote non-aggressive child discipline techniques and reinforce the negative consequences of spanking. Importantly, both mothers and fathers are in need of this information. Innovative efforts to educate and engage fathers are warranted. Father involvement may increase the effectiveness of education and intervention (Bagner \& Eyberg, 2003). Materials may be most effective when they focus on the unique motivations and barriers to parenting faced by fathers (Dubowitz, Lane, Greif, Jensen, \& Lamb, 2006). Outreach may be improved by targeting fathers early in their children's lives, for example, in hospitals at the child's birth and during the first year, a time when resident and nonresident fathers alike are highly engaged with their children.

\section{References}

Achenbach, T. M., \& Rescorla, L. A. (2000). Manual for the ASEBA preschool forms and profiles. Burlington, VT: University of Vermont, Research Center for Children, Youth \& Families

Altschul, I., \& Lee, S. J. (2011). Direct and mediated effects of nativity and other indicators of acculturation on Hispanic mothers' use of physical aggression. Child Maltreatment, 16(4), 262-274

Bagner, D. M., \& Eyberg, S. M. (2003). Father involvement in parent training: When does it matter? Journal of Clinical Adolescent Psychology, 32(4), 599-605.

Bandura, A. (1973). Aggression: A social learning analysis. Englewood Cliffs, NJ: PrenticeHall.

Baumrind, D., Larzelere, R. E., \& Cowan, P. A. (2002). Ordinary physical punishment: Is it harmful? Comment on Gershoff (2002). Psychological Bulletin, 128(4), 580-589.

Beauchaine, T. P., Webster Stratton, C., \& Reid, M. J. (2005). Mediators, moderators, and predictors of 1-year outcomes among children treated for early-onset conduct problems: A latent growth curve analysis. Journal of Consulting and Clinical Psychology, 73(3), 371-388. 
Belsky, J. (1984). The determinants of parenting: A process model. Child Development, 55(1), 83-96.

Benjet, C., \& Kazdin, A. E. (2003). Spanking children: The controveries, findings, and new directions. Clinical Psychology Review, 23, 197-224.

Berlin, L. J., Ispa, J. M., Fine, M. A., Malone, P. S., Brooks-Gunn, J., Brady-Smith, C., et al. (2009). Correlates and consequences of spanking and verbal punishment for low-income White, African American, and Mexican American toddlers. Child Development, 80(5), 1403-1420.

Black, D. A., Heyman, R. E., \& Smith, A. M. (2001). Risk factors for child physical abuse. Aggression and Violent Behavior, 6, 121-188.

Brennan, P. A., Hall, J., Bor, W., Najman, J. M., \& Williams, G. (2003). Integrating biological and social processes in relation to early-onset persistent aggression in boys and girls. Developmental Psychology, 39(2), 309-323.

Cabrera, N. J., Shannon, J. D., \& Tamis-LeMonda, C. (2007). Fathers' influence on their children's cognitive and emotional development: From toddlers to pre-k. Applied Developmental Science, 11, 208-213.

Campbell, S. B., Pierce, E. E., Moore, G., Marakovitz, S., \& Newby, K. (1996). Boys' externalizing problems at elementary school age: Pathways from early behavior problems, maternal control, and family stress. Developmental Psychopathology, 8(4), 701-719.

Carlson, M. J., \& McLanahan, S. S. (2010). Fathers in fragile families. In M. E. Lamb (Ed.), The role of the father in child development (5th ed.). New Jersey: Wiley \& Sons.

Day, R. D., Peterson, G. W., \& McCracken, C. (1998). Predicting spanking of younger and older children by mothers and fathers. Journal of Marriage and the Family, 60(1), 79-94.

Deater-Deckard, K., Ivy, L., \& Petrill, S. A. (2006). Maternal warmth moderates the link between physical punishment and child externalizing problems: A parentoffspring behavior genetic analysis. Parenting: Science \& Practice, 6(1), 59-78.

Dubowitz, H., Lane, W., Greif, G., Jensen, T., \& Lamb, M. (2006). Low-income African American fathers' involvement in children's lives: Implications for practitioners. Journal of Family Social Work, 10(1), 25-41.

Durrant, J. E. (2007). Positive discipline: What it is and how to do it. Bangkok, Thailand: Save the Children Sweden Southeast Asia and the Pacific.

Eckenrode, J., Ganzel, B., Henderson, C. R., Smith, E., Olds, D., Powers, J., et al. (2000). Preventing child abuse and neglect with a program of nurse home visitation: The limiting effects of domestic violence. Journal of the American Medical Association, 284, 1385-1391.

Ferguson, C. J. (2012). Spanking, corporal punishment and negative long-term outcomes: A meta-analytic review of longitudinal studies. Clinical Psychology Review, 33(1), 196-208.

Gershoff, E. T. (2002). Corporal punishment by parents and associated child behaviors and experiences: A meta-analytic and theoretical review. Psychological Bulletin, 128(4), 539-579.

Gershoff, E. T., Grogan-Kaylor, A., Lansford, J. E., Chang, L., Zelli, A., Deater-Deckard, K., et al. (2010). Parent discipline practices in an international sample: Associations with child behaviors and moderation by perceived normativeness. Child Development, $81(2), 487-502$.

Grogan-Kaylor, A. (2004). The effect of corporal punishment on antisocial behavior in children. Social Work Research, 28(3), 153-162.

Grogan-Kaylor, A. (2005). Corporal punishment and the growth trajectory of children's antisocial behavior. Child Maltreatment, 10(3), 283-292.

Guzzo, K. B., \& Lee, H. (2008). Couple relationship status and patterns in early parenting practices. Journal of Marriage and the Family, 70(1), 44-61.

Kaminski, J. W., Valle, L. A., Filene, J. H., \& Boyle, C. L. (2008). A meta-analytic review of components associated with parent training program effectiveness. Journal of Abnormal Child Psychology, 36, 567-589.

Kandel, D. B., \& Wu, P. (1995). Disentangling mother-child effects in the development of antisocial behavior. In J. McCord (Ed.), Coercion and punishment in long-term perspectives (pp. 106-123). New York: Cambridge University Press.

Kessler, R. C., Andrews, G., Mroczek, D., Ustun, B., \& Wittchen, H. U. (1998). The World Health Organization Composite International Diagnostic Interview Short-form (CIDI-SF). International Journal of Methods in Psychiatric Research, 7(4), 171-185.

Koblinsky, S. A., Kuvalanka, K. A., \& Randolph, S. M. (2006). Social skills and behavior problems of urban, African American preschoolers: Role of parenting practices, family conflict, and maternal depression. The American Journal of Orthopsychiatry, 76(4), 554-563.

Lansford, J. E., Criss, M. M., Dodge, K. A., Shaw, D. S., Pettit, G. S., \& Bates, J. E. (2009). Trajectories of physical discipline: Early childhood antecedents and developmental outcomes. Child Development, 80(5), 1385-1402.

Larzelere, R. E., \& Kuhn, B. R. (2005). Comparing child outcomes of physical punishment and alternative disciplinary tactics: A meta-analysis. Clinical Child and Family Psychology Review, 8, 1-37.

Lee, S. J., Altschul, I., \& Gershoff, E. T. (2013). Does warmth moderate longitudinal associations between maternal spanking and child aggression in early childhood? Developmental Psychology (in press).

Lee, S. J., Altschul, I., Shair, S. R., \& Taylor, C. A. (2011a). Hispanic fathers and risk for maltreatment in father-involved families of young children. Journal of the Society for Social Work Research, 2(2), 125-142.

Lee, S. J., Lansford, J. E., Pettit, G. S., Bates, J. E., \& Dodge, K. A. (2012). Parental agreement of reporting parent to child aggression using the Conflict Tactics Scales. Child Abuse E Neglect, 36, 510-518.

Lee, S. J., Perron, B. E., Taylor, C. A., \& Guterman, N. B. (2011b). Paternal psychosocial characteristics and corporal punishment of their 3-year-old children. Journal of Interpersonal Violence, 26(1), 71-87.

Lloyd, S. (1996). Physical aggression, distress, and everyday marital interaction. In D. D. Cahn, \& S. A. Lloyd (Eds.), Family violence from a communication perspective (pp. 177-198). Thousand Oaks, CA: Sage.
Lundahl, B., Tollefson, D., Risser, H., \& Lovejoy, M. C. (2008). A meta-analysis of father involvement in parent training. Research on Social Work Practice, 18(2), 97-106.

Maguire-Jack, K., Gromoske, A. N., \& Berger, L. M. (2012). Spanking and child development during the first five years of life. Child Development, 83(6), 1960-1977.

Manganello, J. A., \& Taylor, C. A. (2009). Television exposure as a risk factor for aggressive behavior among 3-year-old children. Archives of Pediatrics and Adolescent Medicine, 163(11), 1037-1045.

Martin, A., Ryan, R. M., \& Brooks-Gunn, J. (2007). The joint influence of mother and father parenting on child cognitive outcomes at age 5. Early Child Research Quarterly, 22, 423-439.

McFarlane, J. M., Groff, J. Y., O'Brien, J. A., \& Watson, K. (2003). Behaviors of children who are exposed and not exposed to intimate partneer violence: An analysis of 330 Black, White, and Hispanic children. Pediatrics, 112(3), e202-e207.

Meadows, S. O., McLanahan, S. S., \& Brooks-Gunn, J. (2007). Parental depression and anxiety and early childhood behavior problems across family types. Journal of Marriage and the Family, 69(5), 1162-1177.

Morris, S. Z., \& Gibson, C. L. (2011). Corporal punishment's influence on children's aggressive and delinquent behavior. Criminal Justice and Behavior, 38(8), 818-839.

National Institute on Alcohol Abuse and Alcoholism (2005). Helping patients who drink too much: A clinician's guide, updated 2005 edition. Last accessed: October 17, 2012. http://pubs.niaaa.nih.gov/publications/Practitioner/CliniciansGuide2005/ clinicians guide.htm

Owens, E. B., \& Shaw, D. S. (2003). Predicting growth curves of externalizing behavior across the preschool years. Journal of Abnormal Child Psychology, 31(6), 575-590.

Prinzie, P., Onghena, P., \& Hellinckx, W. (2006). A cohort-sequential multivariate latent growth curve analysis of normative $\mathrm{CBCL}$ aggressive and delinquent problem behavior: Associations with harsh discipline and gender. International Journal of Behavioral Development, 30(5), 444-459.

Raikes, H. H., Summers, J. A., \& Roggman, L. A. (2005). Father involvement in Early Head Start programs. Fathering, 3(1), 29-58.

Reichman, N. E., Teitler, J. O., Garfinkel, I., \& McLanahan, S. S. (2001). Fragile families: Sample and design. Child and Youth Services Review, 32, 303-326.

Runyan, D. K., Cox, C. E., Dubowitz, H., Newton, R. R., Upadhyaya, M., Kotch, J. B., et al. (2005). Describing maltreatment: Do child protective service reports and research definitions agree? Child Abuse \& Neglect, 29(5), 461-477.

Ryan, R. M., Martin, A., \& Brooks-Gunn, J. (2006). Is one good parent good enough? Patterns of mother and father parenting and child cognitive outcomes at 24 and 6 months. Parenting: Science and Practice, 6(2), 211-228.

Scholer, S. J., Brokish, P. A., Mukherjee, A. B., \& Gigante, J. (2008a). A violenceprevention program helps teach medical students and pediatric residents about childhood aggression. Clinical Pediatrics, 47(9), 891-900.

Scholer, S. J., Hudnut-Beumler, J., \& Dietrich, M. S. (2010). A brief primary care intervention helps parents develop plans to discipline. Pediatrics, 125(2), e242-e249.

Scholer, S. J., Nix, R. L., \& Patterson, B. (2006). Gaps in pediatricians' advice to parents regarding early childhood aggression. Clinical Pediatrics, 45, 23-28.

Scholer, S. J., Walkowski, C. A., \& Bickman, L. (2008b). Voluntary or required viewing of a violence prevention program in pediatric primary care. Clinical Pediatrics, 47(5), 461-468.

Singer, J. L., Singer, D. G., \& Rapaczynski, W. S. (1984). Family patterns and television viewing as predictors of children's beliefs and aggression. Journal of Communication, 34(2), 73-89.

Slep, A. M. S., \& O'Leary, S. G. (2005). Parent and partner violence in families with young children: Rates, patterns, and connections. Journal of Consulting and Clinical Psychology, 73(3), 435-444.

Smith, B. L. (2012). The case against spanking: Physical discipline is slowly declining as some studies reveal lasting harms for children. Monitor on Psychology, 43(4), 60-63.

Sourander, A., \& Helstelä, L. (2005). Childhood predictors of externalizing and internalizing problems in adolescence. European Child E Adolescent Psychiatry, 14(8), 415.

Straus, M. A., Hamby, S. L., Boney-McCoy, S., \& Sugarman, D. B. (1996). The Revised Conflict Tactics Scale (CTS2): Development and preliminary psychometric data. Journal of Family Issues, 17, 283-316.

Straus, M. A., Hamby, S. L., Finkelhor, D. W., Moore, D. W., \& Runyan, D. (1998). Identification of child maltreatment with the Parent-Child Conflict Tactics Scales: Development and psychometric data for a national sample of American parents. Child Abuse \&' Neglect, 22, 249-270.

Straus, M. A., \& Stewart, J. H. (1999). Corporal punishment by American parents: National data on prevalence, chronicity, severity, and duration, in relation to child and family characteristics. Clinical Child and Family Psychology, 2, 55-70.

Tamis-LeMonda, C. S., Shannon, J. D., Cabera, N. J., \& Lamb, M. E. (2004). Fathers and mothers at play with their 2-and-3-year-olds: Contributions to language and cognitive development. Child Development, 75(6), 1806-1820.

Taylor, C. A., Al-Hiyari, R., Lee, S. J., Priebe, A. E., \& Wiggleton, L. (2013). Attitudes and ideologies linked with approval of corporal punishment in the U.S.: An online comment content analysis. (Manuscript Submitted for Review).

Taylor, C. A., Guterman, N. B., Lee, S. J., \& Rathouz, P. (2009). Intimate partner violence, maternal stress, nativity, and risk for maternal maltreatment of young children. American Journal of Public Health, 99(1), 175-183.

Taylor, C. A., Lee, S. J., Guterman, N. B., \& Rice, J. (2010a). Use of spanking for 3-year-old children and associated intimate partner aggression or violence. Pediatrics, 126(3), 415-424.

Taylor, C. A., Manganello, J. A., Lee, S. J., \& Rice, J. (2010b). Mothers' spanking of 3-year-old children and subsequent risk of children's aggressive behavior. Pediatrics, 125(5), e1057-e1065.

Vittrup, B., \& Holden, G. W. (2010). Children's assessments of corporal punishment and other disciplinary practices: The role of age, race, SES, and exposure to spanking. Journal of Applied Developmental Psychology, 31, 211-220. 
Voisine, S., \& Baker, A. J. L. (2012). Do universal parenting programs discourage parents from using corporal punishment: A program review. Families in Society, 93(3), $212-218$

Weiss, R. L., \& Margolin, G. (1977). Assessment of marital conflict and accord. In A. R Ciminero, K. D. Calhoun, \& H. E. Adams (Eds.), Handbook of behavioral assessment (pp. 555-602). New York: John Wiley.
Winsler, A., Madigan, A. L., \& Aquilino, S. A. (2005). Correspondence between maternal and paternal parenting styles in early childhood. Early Child Research Quarterly, 20, $1-12$.

Zolotor, A. J., Theodore, A. D., Chang, J. J., Berkoff, M. C., \& Runyan, D. K. (2008). Speak softly-and forget the stick: Corporal punishment and child physical abuse. American Journal of Preventative Medicine, 35(4), 364-369. 